\title{
Multi-item economic production quantity model for imperfect items with multiple production setups and rework under the effect of preservation technology and learning environment
}

\author{
Preeti Jawla ${ }^{a^{*}}$ and S. R. Singh ${ }^{\mathrm{b}}$
}

${ }^{a}$ Department of Mathematics, Banasthali University, Rajasthan, 304022, India

${ }^{b}$ School of Mathematics, D.N. College, Meerut, 250001, India

\section{CHRON I C LE}

Article history:

Received November 42015

Received in Revised Format

December 212015

Accepted February 182016

Available online

February 192016

Keywords:

Multi-item

Selling price dependent demand

Preservation

Variable holding cost

Volume flexibility

Learning

Rework

Inflation

Multiple production setups

Imperfect production

\begin{abstract}
A B S T R A C T
This study aims to investigate the multi-item inventory model in a production/rework system with multiple production setups. Rework can be depicted as the transformation of production rejects, failed, or non-conforming items into re-usable products of the same or lower quality during or after inspection. Rework is very valuable and profitable, especially if materials are limited in availability and also pricey. Moreover, rework can be a good contribution to a 'green image environment'. In this paper, we establish a multi-item inventory model to determine the optimal inventory replenishment policy for the economic production quantity (EPQ) model for imperfect, deteriorating items with multiple productions and rework under inflation and learning environment. In inventory modelling, Inflation plays a very important role. In one cycle, production system produces items in $\mathrm{n}$ production setups and one rework setup, i.e. system follows $(n, 1)$ policy. To reduce the deterioration of products preservation technology investment is also considered in this model. Holding cost is taken as time dependent. We develop expressions for the average profit per time unit, including procurement of input materials, costs for production, rework, deterioration cost and storage of serviceable and reworkable lots. Using those expressions, the proposed model is demonstrated numerically and the sensitivity analysis is also performed to study the behaviour of the model.
\end{abstract}

\section{Introduction}

In the manufacturing firm, when parts are produced instead of being purchased from outside merchants, the economic production quantity model is often used to deal with the instantaneous or non-instantaneous inventory replenishment rate in order to maximize the expected overall profit per unit time. Due to the simplicity of EPQ models they have been used mostly, and are still applied industry-wide today; and many production-inventory models with more complicated and/or practical features were studied broadly during the past decades. We assume in the classic EPQ models that all the produced items are of perfect quality. However, in real-life production systems, due to process deterioration and/or other factors, 
evulsions of imperfect quality items are unavoidable. Studies have been carried out to eke the EPQ model by addressing the issue of produced imperfect quality items.

Porteus (1986) was the first who avowedly elaborate the significant relationship between lot size and quality of the item. Lee and Rosenblatt (1987) considered that product quality is normally affected by the state of the production process, which may shift from an "in-control" state to an "out-of-control" state and produce defective items. Salameh and Jaber (2000) hypothesized that production process may also produce imperfect quality products and items of imperfect quality could be used in another production/inventory situation that is less restrictive process and acceptance. However, as the production of defective or imperfect products is a naturalistic expectation, it will be more practical and close to reality, to integrate quality considerations of the items into the classical models to deal with real life manufacturing conditions.

Sometimes produced defective items can be repaired and reworked. For instance, manufacturing processes in printed circuit board assembly, or in other industries such as metal components, chemical, textiles, or in plastic injection moulding, etc., sometimes employs rework as a suitable and acceptable process in terms of level of quality. During the last decade, interest in rework on optimal replenishment decisions has been grown-up extensively. Gupta and Chakraborty (1984) considered that rejected items can be reworked. They obtained an economic batch quantity model by considering recycling from the last stage to the first stage. Hayek and Salameh (2001) discussed an economic manufacturing-inventory model considering all produced defective items are repairable and obtained an optimal policy for the EMQ model under the effect of reworking all defective items.

An inventory model is developed by Chiu (2003) to derive an optimal operating policy for a finite production inventory model with scrap, reworking of repairable defective items, random defective rate and backlogging policy including lot size backordering levels that minimized overall inventory costs. Inderfuth et al. (2005) considered an EPQ model with rework and deteriorating repairable products. Since the repairable products deteriorate, it will increase rework time and also rework cost per unit. Feng and Viswanathan (2011) proposed mathematical models for general multi manufacturing and remanufacturing setup policies. Singh et al. (2012) studied an economic production lot size model with volume flexibility and rework under shortages.

Deterioration of items present in inventory had been studied in the past decades (Dave \& Patel, 1981; Hariga, 1996; Teng et al., 1999; Yadav et al., 2012a). In that literature, researchers discussed about different type of deterioration rates which may be time dependent or constant. The deterioration of goods is a natural phenomenon and plays an important role in inventory system. There are some products like as Foods, drugs, pharmaceuticals etc. in which sufficient deterioration can take place at a point. Deterioration cannot be stopped; however, it can be slowed down by some specialized techniques and equipment or processes when items are at risks of deterioration and obsolescence. For example, when food is preserved and packaged then there it will not stable forever, but deteriorates slowly to the point where it will unacceptable. Cold storage slows the deterioration of color materials and film. Low temperatures, such as refrigeration, help prevent and slow the microbial spoilage and chemical deterioration. Consequently, the rate of deterioration of deteriorating items depends on the investment in the preservation technology of the inventory at the facility as well as the latter' senvironmental conditions.

However, in the inventory management system investigation on preservation technology has received little attention in the past years. The consideration of preservation technology in the inventory system is important due to the fact that preservation technology can reduce the deterioration rate extensively. Accordingly, Hsu et al. (2010) first investigated the impact of preservation technology investment on an exponentially decaying inventory model involving partial backorders. Dye (2013) then extended the model of Hsu et al. (2010) to a generalized deteriorating inventory system. He showed that a higher preservation technology investment leads to a higher service rate and makes more profit. Singh and 
Sharma (2013) considered preservation technology investment to model the finite time horizon inventory problem of deteriorating items that are subject to the supplier's trade credit. Shastri et al. (2014) presented an EOQ inventory model for a retailer under two-levels of trade credit to reflect the supply chain management (SCM) by using preservation technology to increase the potential worth of the deteriorated items. More recently, Tsao (2014) extended the model of Dye (2013) to consider a joint location and preservation technology investment decision-making problem for non-instantaneous deteriorating items under trade credit.

Learning curves have been receiving increasing attention by practitioners and researchers (Yelle, 1979; Belkaoui, 1986; Lai, 1995). The earliest learning curve representation is a geometric progression that expresses the decreasing time required to accomplish any repetitive operation. The form of the learning curve has been debated by many researchers and practitioners. The Wright's learning curve (WLC; Wright, 1936) is the earliest model observed in an industrial setting. The power form of the classical learning curve (WLC; Wright, 1936) states that total time per unit decreases as the cumulative number of units produced increases. Crossman (1959) claimed that the learning process continues even after 10 million repetitions. The authors recommend Dar-El (2000) for additional reading on learning processes. The impact of reworks on process yield and some works have analyzed the effect of lot learning on product quality with rework process. Laprè et al. (2000) derived a quality learning curve that links different types of learning in quality improvement projects to the evolution of a factory's waste rate and he shows that the waste rate declines over time according to a learning curve relationship. Jaber and Bonney (2003) observed that the time required to rework a defective item reduces as production increases and that rework times conform to the learning relationship described by Wright (1936). Jaber and Khan (2010) integrated several of the aspects mentioned above by studying lot splitting in an imperfect serial production system for learning effects with rework and scrap at each stage. Glock and Jaber (2013) developed a multi-stage production-inventory model with rework and scrap under the learning and forgetting effects.

In this paper, we emphasize the importance of paying attention to rework of defective items, learning on cost and preservation technology investment to reduce deterioration when making lot sizing decisions. In our lot sizing model for deteriorated items with rework, both serviceable and recoverable items are deteriorating with time. In this paper, we consider a volume flexible (see Sethi \& Sethi, 1990) production system with price dependent demand. In this multi-item inventory system, items are inspected after production. Good quality items are stocked and sold to customer immediately. Defective items scheduled for rework. We assume all recoverable items after rework are considered "as new". Rework process is not done immediately after the production process, but it waits until a determined number of production setups. Inflation is considered in this model. Inflation plays a very significant role in inventory models. Inflation refers to the movement in the general level of prices. Holding cost is taken as time dependent. The objective of this paper is to determine the optimal replenishment scheme to maximize the total average profit for the inventory system over an infinite planning horizon.

The structure of the remainder of the paper is organized as follows. The notations and assumptions required for the mathematical formulations are introduced in the next section. The formulation and the development of the model are made in section 3. In Section 4, we illustrate the theoretical results with the numerical verification and the results of a sensitivity analysis are discussed to illustrate the features of the proposed model. Finally, the conclusions and suggestions for future research are given in Section 5 .

\section{Formulation Of The Model With Assumptions And Notations}

The production-inventory model is developed with the following assumptions and notations. 


\subsection{Assumptions}

- This is a multi-item production inventory model

- Time horizon is infinite.

- In this model it is assumed that demand is a power function of price per unit i. e. $D(s)=$ $a_{i} s^{-b}$, where $a_{i}, b>0$.

- The production cost per unit item is a function of the production rate and given by $\eta\left(p_{i}\right)=M+\frac{G}{p_{i}}+H p_{i}$, where $\mathrm{M}, \mathrm{G}, \mathrm{H}$ all are positive constants. This cost is based on the following factors:

1. The material cost $M$ per unit item is fixed.

2. As the production rate increases, some costs like energy and labour costs are equally distributed over a large number of units. Hence the production cost per unit $(\mathrm{G} / \mathrm{p})$ decreases as the production rate $(\mathrm{p})$ increases.

3. The third term (Hp), associated with tool/die costs, and is proportional to the production rate.

- No machine breakdown occurs in the production run and rework period.

- Deteriorating rate is constant and there is replacement for a deteriorated item.

- Defective items are generated only during production period. Rework process results in only good quality items.

- Preservation technology is used to reduce the decay rate of items.

- No shortages are permitted; the rate of producing good quality items and rework must be greater than the demand rate.

- The rate of producing good quality items should be greater than the sum of the demand rate and the deteriorating rate.

- Effect of learning and Inflation are considered.

- Holding cost is taken to be variable in nature.

- Lead time is taken as negligible.

\subsection{Notations}

$D(s)$ : demand rate of the customers

$\theta$ : Original deterioration rate of on-hand-stock, $\theta>0$

$\xi$ : Preservation technology $(\mathrm{PT})$ cost for reducing deterioration rate in order to preserve the products, $\xi \geq 0$.

$\theta_{s}$ : Resultant deterioration rate, $\theta_{s}=\theta-\omega(\xi)$ for serviceable items.

$\omega(\xi)$ : Reduced deterioration rate, a function of $\xi$

$\theta_{R}$ : Resultant deterioration rate, $\theta_{R}=\theta-\pi(\xi)$ for recoverable items.

$\pi(\xi)$ : Reduced deterioration rate, a function of $\xi$

p: production rate

$p_{R}:$ rework process rate

$\alpha:$ percentage of good quality items

$\mathrm{n}$ : number of production setup in one cycle

$C_{i p}+\frac{C_{p L}}{k^{l}}$ : Production setup cost per cycle with learning effect

$C_{i R}+\frac{C_{R L}}{k^{l}}$ : Rework setup cost per cycle with learning effect

$C_{i d}+\frac{C_{d L}}{k^{l}}$ : deteriorating cost with learning effect

$h_{i s}+\gamma t$ : Unit holding cost per unit per unit time for serviceable items, where $\gamma>0$.

$h_{i R}+\gamma t$ : Unit holding cost per unit per unit time for recoverable items, where $\gamma>0$.

$\mathrm{R}$ : inflation rate

$I_{i 1}$ : Serviceable inventory level in a production period 
$I_{i 2}$ : Serviceable inventory level in a non-production period

$I_{i 3}$ : Serviceable inventory level in a rework production period

$I_{i 4}$ : Serviceable inventory level in a rework non-production period

$I_{i S 1}$ : Total serviceable inventory in a production period

$I_{i S 2}$ : Total serviceable inventory in a non-production period

$I_{i S 3}$ : Total serviceable inventory in a rework production period

$I_{i S 4}$ : Total serviceable inventory in a rework non-production period

$I_{i r 1}$ : Recoverable inventory level in a production period

$I_{i r 2}$ : Recoverable inventory level in a non-production period

$I_{\text {ir } 3}$ : Recoverable inventory level in a rework production period

$I_{i R 1}$ : Total recoverable inventory in a production period

$I_{i R 2}$ : Total recoverable inventory in a non-production period

$T R I_{p i}$ : Total recoverable inventory in $\mathrm{n}$ production periods

$T R I_{N i}$ : Total recoverable inventory in $\mathrm{n}$ non-production periods

$T R I_{R i}$ : Total recoverable inventory in a rework production period

TRI : Total recoverable inventory of the inventory system

$I_{i R I}$ : Maximum inventory level of recoverable items in a production setup

$I_{M R i}$ : Maximum inventory level of recoverable items when rework process started

$T_{i 1}$ : Production period

$T_{i 2}:$ Non production period

$T_{i 3}$ : Rework process period

$T_{i 4}$ : Non rework process period

TAP : Total average profit of the inventory system

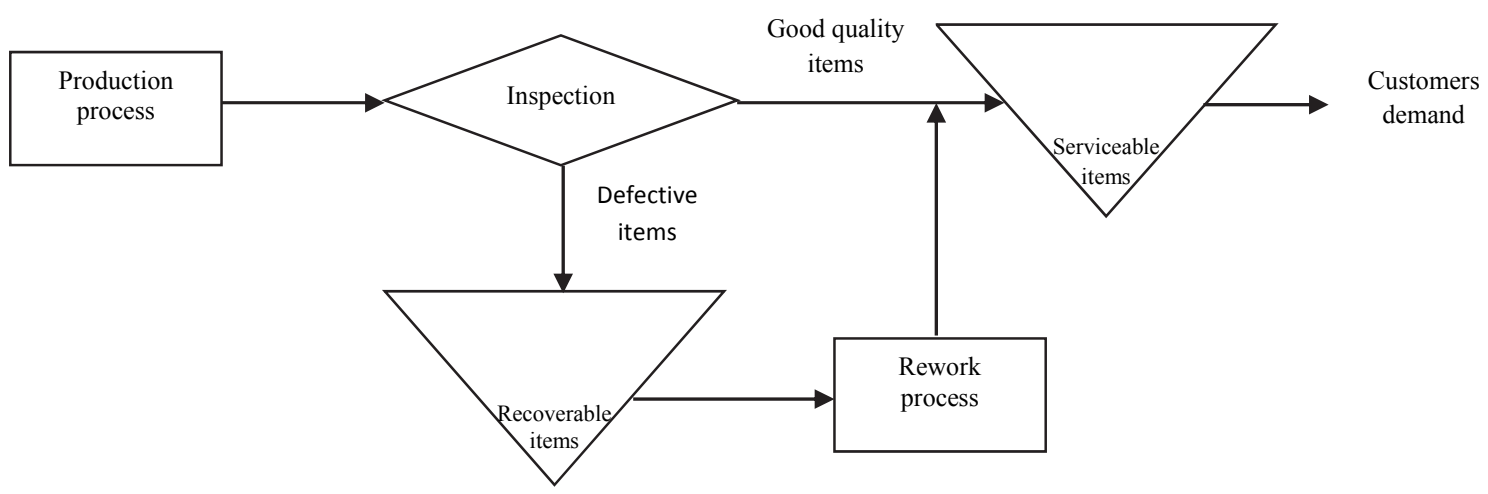

Fig. 1. The production system with rework

\section{Model Formulation Of The Inventory System}

\subsection{Model Formulation}

According to the notation and assumptions mentioned above, the behaviour of the inventory level of serviceable items in three productions is exhibited in Fig. 2. From Fig. 2, it can be seen that Production is performed during $T_{i 1}$ time period. When production is established and the stock level reaches its maximum, there are $(1-\alpha) p$ products defect per unit time. There work process starts after a predetermined production up time and production setups. During $T_{i 2}$ time period, the depletion of the inventory occurs due to the combined effects of demand and deterioration. The rework process is done during $T_{i 3}$ time period. In this model we have assume that the production processes of material and product defect are different, rework rate is not the same as the production rate. 
The inventory level in a production period, non-production period, rework production period and rework non-production period from the serviceable items can be illustrated by the following equation:

$$
\begin{array}{ll}
I_{i 1}^{\prime}(t)+\theta_{s} I_{i 1}(t)=\alpha_{i} p_{i}-D_{i}(s), & 0 \leq t_{i 1} \leq T_{i 1} \\
I_{i 2}^{\prime}(t)+\theta_{s} I_{i 2}(t)=-D_{i}(s), & 0 \leq t_{i 2} \leq T_{i 2} \\
I_{i 3}^{\prime}(t)+\theta_{s} I_{i 3}(t)=p_{r i}-D_{i}(s), & 0 \leq t_{i 3} \leq T_{i 3} \\
I_{i 4}^{\prime}(t)+\theta_{s} I_{i 4}(t)=-D_{i}(s), & 0 \leq t_{i 4} \leq T_{i 4}
\end{array}
$$

With the boundary condition $I_{i 1}\left(T_{i 1}=0\right)=0, I_{i 1}\left(T_{i 2}\right)=0, I_{i 1}\left(T_{i 3}=0\right)=0$ and $I_{i 1}\left(T_{i 4}\right)=0$, solving the differential equations

From Eq. (1), the inventory level in a production period is

$$
I_{i 1}\left(t_{i 1}\right)=\frac{1}{\theta_{s}}\left(\alpha_{i} p_{i}-a_{i} s^{-b}\right)\left(1-e^{-\theta_{s} t_{i 1}}\right)
$$

The total inventory in a production up time from equation (5) can be calculated as:

$$
\begin{aligned}
& I_{i S 1}=\int_{0}^{T_{i 1}} \frac{1}{\theta_{s}}\left(\alpha_{i} p_{i}-a_{i} s^{-b}\right)\left(1-e^{-\theta_{s} t_{i 1}}\right) d t_{i 1}, \\
& I_{i S 1}=\frac{1}{\theta_{s}}\left(\alpha_{i} p_{i}-a_{i} s^{-b}\right) \frac{\left(\theta_{s} T_{i 1}+e^{-\theta_{s} T_{i 1}}-1\right)}{\theta_{s}}
\end{aligned}
$$

From Eq. (2), the inventory level in a non-production period is

$$
I_{i 2}\left(t_{i 2}\right)=\frac{a_{i} s^{-b}}{\theta_{s}}\left(e^{\theta_{s}\left(T_{i 2}-t_{i 2}\right)}-1\right)
$$

The total inventory in a non-production up time from equation (7) can be calculated as:

$$
\begin{aligned}
& I_{i S 2}=\int_{t_{i 2}=0}^{T_{i 2}} \frac{a_{i} s^{-b}}{\theta_{s}}\left(e^{\theta_{s}\left(T_{i 2}-t_{i 2}\right)}-1\right) d t_{i 2}, \\
& I_{i S 2}=\frac{a_{i} s^{-b}}{\theta_{s}}\left(\frac{e^{\theta_{s} T_{i 2}}-1-\theta_{s} T_{i 2}}{\theta_{s}}\right)
\end{aligned}
$$

From Eq. (3), The inventory level in a rework production period is

$$
I_{i 3}\left(t_{i 3}\right)=\frac{1}{\theta_{s}}\left(p_{r i}-a_{i} s^{-b}\right)\left(1-e^{-\theta_{s} t_{i 3}}\right)
$$

The total inventory in a rework production up time from equation (9) can be modelled as:

$$
\begin{aligned}
& I_{i S 3}=\int_{t_{i 3}=0}^{T_{i 3}} \frac{1}{\theta_{s}}\left(p_{r i}-a_{i} s^{-b}\right)\left(1-e^{-\theta_{s} t_{i 3}}\right) d t_{i 3}, \\
& I_{i S 3}=\frac{1}{\theta_{s}}\left(p_{r i}-a_{i} s^{-b}\right)\left(\frac{\theta_{s} T_{i 3}+e^{-\theta_{s} T_{i 3}}-1}{\theta_{s}}\right)
\end{aligned}
$$




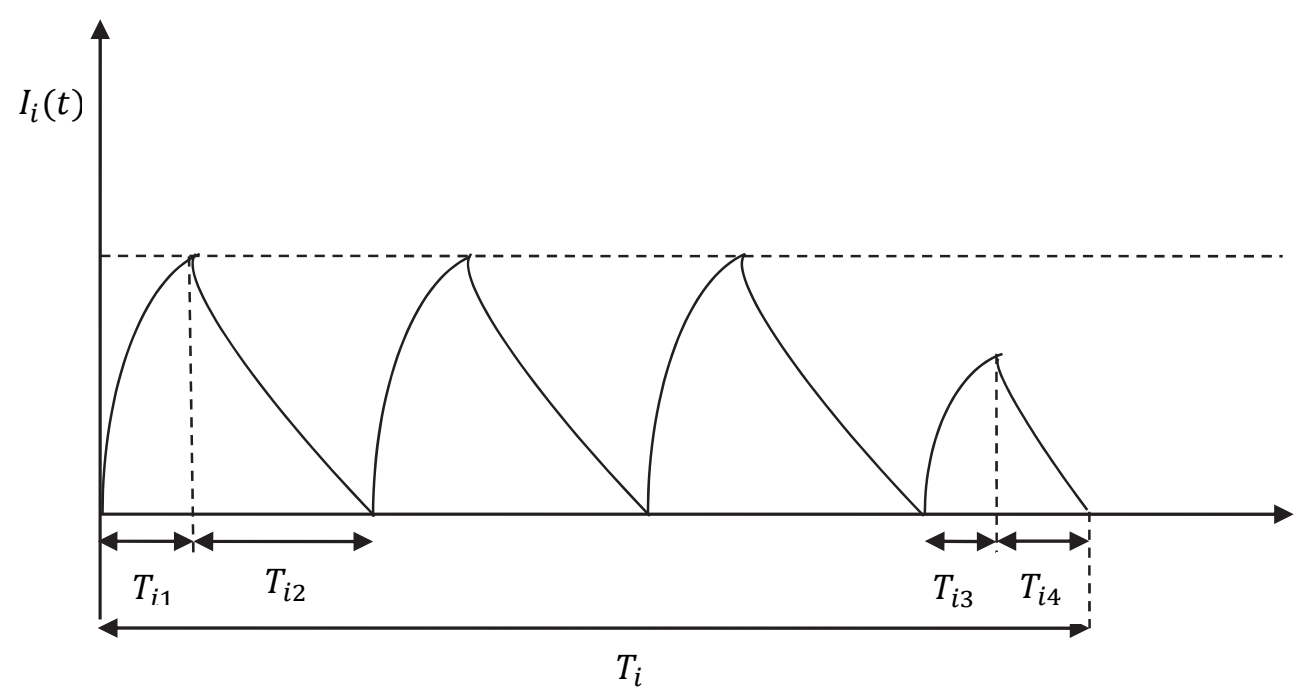

Fig. 2. Serviceable inventory level of 3 production setups and 1 rework setup

From Eq. (4), The inventory level in a rework non-production period is

$$
I_{i 4}\left(t_{i 4}\right)=\frac{a_{i} s^{-b}}{\theta_{s}}\left(e^{\theta_{s}\left(T_{i 4}-t_{i 4}\right)}-1\right)
$$

The total inventory in a rework non-production up time from Eq. (11) can be modelled as:

$$
\begin{aligned}
I_{i S 4} & =\int_{t_{i 4}=0}^{T_{i 4}} \frac{a_{i} s^{-b}}{\theta_{s}}\left(e^{\theta_{s}\left(T_{i 4}-t_{i 4}\right)}-1\right) d t_{i 4}, \\
I_{i S 4} & =\frac{a_{i} s^{-b}}{\theta_{s}}\left(\frac{e^{\theta_{s} T_{i 4}}-1-\theta_{s} T_{i 4}}{\theta_{s}}\right)
\end{aligned}
$$

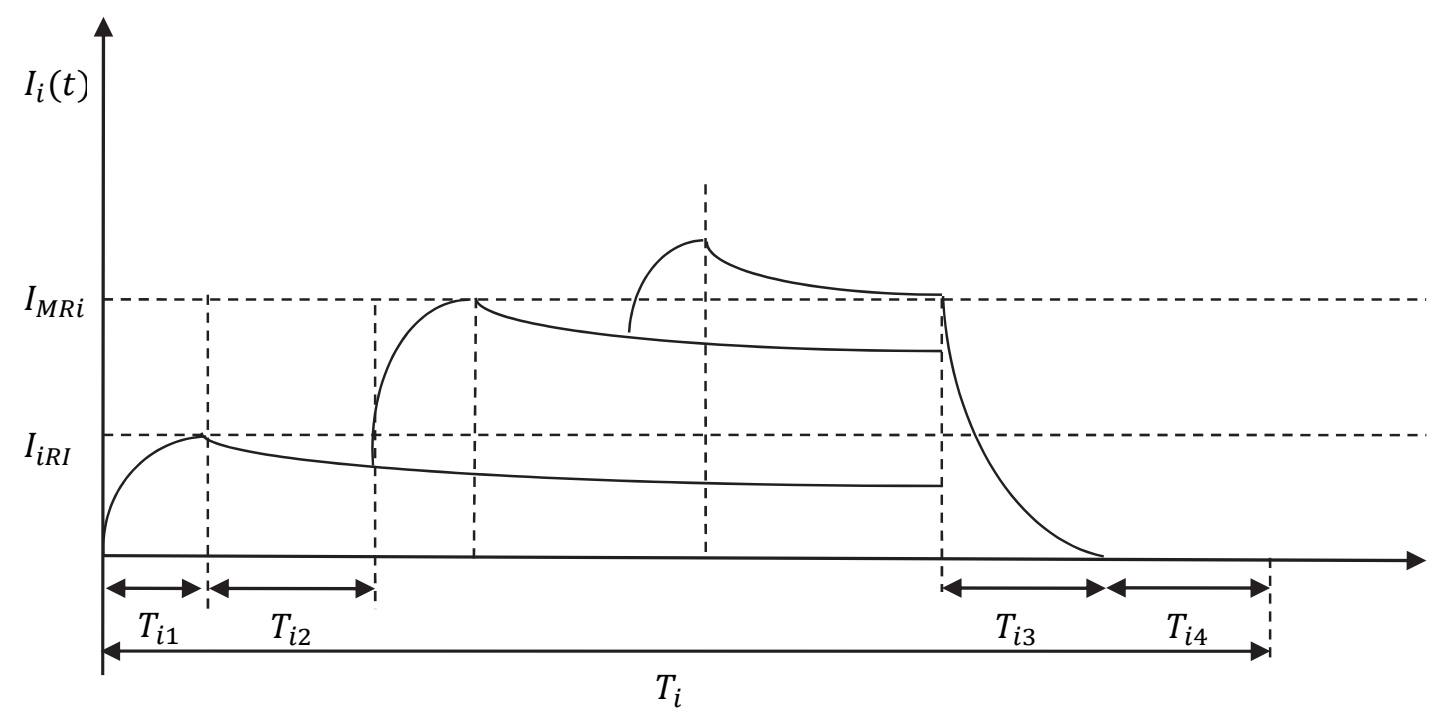

Fig. 3. Recoverable inventory level of 3 production setups and 1 rework setup

The inventory level of recoverable items in a production period, non-production period and rework period can be formulated by the following equation: 


$$
\begin{array}{lc}
I_{i r 1}^{\prime}\left(t_{i r 1}\right)+\theta_{R} I_{i r 1}\left(t_{i r 1}\right)=\left(1-\alpha_{i}\right) p_{i}, & 0 \leq t_{i r 1} \leq T_{i 1} \\
I_{i r 2}^{\prime}\left(t_{i r 2}\right)+\theta_{R} I_{i r 2}\left(t_{i r 2}\right)=0, & 0 \leq t_{i r 2} \leq(n-1) T_{i 1}+n T_{i 2} \\
I_{i r 3}^{\prime}\left(t_{i r 3}\right)+\theta_{R} I_{i r 3}\left(t_{i 3}\right)=-p_{i r}, & 0 \leq t_{i r 3} \leq T_{i 3}
\end{array}
$$

With the boundary condition $I_{i r 1}(0)=0, I_{i r 2}(0)=I_{i R I}$ and $I_{i 1}\left(T_{i 3}\right)=0$, solving the differential equations

From Eq. (13), the inventory level of recoverable items in a production period is

$$
I_{i r 1}\left(t_{i r 1}\right)=\frac{\left(1-\alpha_{i}\right) p_{i}}{\theta_{R}}\left(1-e^{-\theta_{R} t_{i r 1}}\right)
$$

The total inventory level of recoverable items in a production up time can be modelled as:

$$
\begin{aligned}
I_{i R 1} & =\int_{t_{i 11}=0}^{T_{i 1}} \frac{\left(1-\alpha_{i}\right) p_{i}}{\theta_{R}}\left(1-e^{-\theta_{R} t_{i r 1}}\right) d t_{i r 1}, \\
I_{i R 1} & =\frac{\left(1-\alpha_{i}\right) p_{i}}{\theta_{R}}\left(\frac{\theta_{R} T_{i 1}-e^{-\theta_{R} T_{i 1}}-1}{\theta_{R}}\right)
\end{aligned}
$$

Since there are $\mathrm{n}$ production setups in one cycle the total inventory for recoverable items in one cycle is:

$$
\begin{aligned}
& T R I_{p i}=\sum_{1}^{n} \frac{\left(1-\alpha_{i}\right) p_{i}}{\theta_{R}}\left(\frac{\theta_{R} T_{i 1}-e^{-\theta_{R} T_{i 1}}-1}{\theta_{R}}\right) \\
& T R I_{p i}=\frac{n\left(1-\alpha_{i}\right) p_{i}}{\theta_{R}}\left(\frac{\theta_{R} T_{i 1}-e^{-\theta_{R} T_{i 1}}-1}{\theta_{R}}\right)
\end{aligned}
$$

The initial recoverable inventory level in each production setup is equal to $I_{i R I}$ and it can be modelled as:

$$
I_{i R I}=\frac{\left(1-\alpha_{i}\right) p_{i}}{\theta_{R}}\left(1-e^{-\theta_{R} T_{i 1}}\right)
$$

From Eq. (14), the inventory level of recoverable items in a non-production period for each production set up is

$$
I_{i r 2}\left(t_{i r 2}\right)=I_{i R I} \cdot e^{-\theta_{R} t_{i r 2}}
$$

The total inventory level of recoverable items in a non-production up time can be modelled as:

$$
\begin{aligned}
& I_{i R 2}=\int_{t_{i r 2}=0}^{(m-1) T_{i 1}+m T_{i 2}} I_{i R I} e^{-\theta_{R} t_{i r 2}} d t_{i r 2}, \\
& I_{i R 2}=I_{i R I}\left(\frac{1-e^{-\theta_{R}\left((m-1) T_{i 1}+m T_{i 2}\right)}}{\theta_{R}}\right)
\end{aligned}
$$

The total inventory of recoverable items in $\mathrm{n}$ non-production period is

$$
T R I_{N i}=\sum_{m=1}^{n} I_{i R I}\left(\frac{1-e^{-\theta_{R}\left((m-1) T_{i 1}+m T_{i 2}\right)}}{\theta_{R}}\right)
$$

In the end of production cycle, inventory level of recoverable item is equal to maximum inventory level of recoverable items in a production set up reduced by deteriorating rate during production up time and down time. The inventory level can be modelled as: 


$$
I_{M R i}=\sum_{m=1}^{n} I_{i R I} e^{-\theta_{R}\left((m-1) T_{i 1}+m T_{i 2}\right)}
$$

Now substitute $I_{i R I}$ from Eq. (19), we have

$$
I_{M R i}=\sum_{m=1}^{n}\left[\frac{\left(1-\alpha_{i}\right) p_{i}}{\theta_{R}}\left(1-e^{-\theta_{R} T_{i 1}}\right) e^{-\theta_{R}\left((m-1) T_{i 1}+m T_{i 2}\right)}\right]
$$

From Eq. (15), the inventory level of recoverable items in a rework period is

$$
I_{i r 3}\left(t_{i r 3}\right)=\frac{p_{r i}}{\theta_{R}}\left(e^{\theta_{R}\left(T_{i 3}-t_{i r 3}\right)}-1\right)
$$

The total inventory of recoverable items in a rework period can be formulated as:

$$
\begin{aligned}
& T R I_{R i}=\int_{t_{i r 3}=0}^{T_{i 3}} \frac{p_{r i}}{\theta_{R}}\left(e^{\theta_{R}\left(T_{i 3}-t_{i r 3}\right)}-1\right) d t_{i r 3}, \\
& T R I_{R i}=\frac{p_{r i}}{\theta_{R}}\left(\frac{e^{\theta_{R} T_{i 3}}-1-\theta_{R} T_{i 3}}{\theta_{R}}\right)
\end{aligned}
$$

The total recoverable inventory can be formulated as:

$T R I=$ The total inventory for recoverable items in $\mathrm{n}$ production setups + The total inventory for recoverable items in $\mathrm{n}$ non-production setups + The total inventory of recoverable items in a rework period

$$
\begin{gathered}
T R I=T R I_{p i}+T R I_{N i}+T R I_{R i} \\
T R I=\sum_{1}^{n} \frac{\left(1-\alpha_{i}\right) p_{i}}{\theta_{R}}\left(\frac{\theta_{R} T_{i 1}-e^{-\theta_{R} T_{i 1}}-1}{\theta_{R}}\right)+\sum_{m=1}^{n} I_{i R I}\left(\frac{1-e^{-\theta_{R}\left((m-1) T_{i 1}+m T_{i 2}\right)}}{\theta_{R}}\right)+\frac{p_{r i}}{\theta_{R}}\left(\frac{e^{\theta_{R} T_{i 3}}-1-\theta_{R} T_{i 3}}{\theta_{R}}\right)
\end{gathered}
$$

The per cycle cost components for the given inventory model are as follows:

$$
\text { Sales Revenue(SR) } i=\mathrm{s}\left[n\left(\int_{0}^{T_{i 1}} D_{i}(s) e^{-R t} d t+\int_{0}^{T_{i 2}} D_{i}(s) e^{-R t} d t\right)+\int_{0}^{T_{i 3}} D_{i}(s) e^{-R t} d t+\int_{0}^{T_{i 4}} D_{i}(s) e^{-R t} d t\right]
$$

Production setup $\operatorname{Cost}\left(S C_{P}\right)_{i}=n\left(C_{i p}+\frac{C_{p L}}{k^{l}}\right)$

$$
\text { Rework setup } \operatorname{Cost}\left(S C_{R}\right)_{i}=\left(C_{i R}+\frac{C_{R L}}{k^{l}}\right)
$$

Holding Cost for serviceble items $\left(\mathrm{HC}_{S}\right)_{i}=\left[n\left\{\int_{0}^{T_{i 1}}\left(h_{i s}+\gamma t\right) I_{i 1}(t) e^{-R t} d t+\int_{0}^{T_{i 2}}\left(h_{i s}+\gamma t\right) I_{i 2}(t) e^{-R t} d t\right\}+\int_{0}^{T_{i 3}}\left(h_{i s}+\gamma t\right) I_{i 3}(t) e^{-R t} d t\right.$

$$
\left.+\int_{0}^{T_{i 4}}\left(h_{i s}+\gamma t\right) I_{i 4}(t) e^{-R t} d t\right]
$$

Holding Cost for recoverable items $\left(\mathrm{HC}_{R}\right)_{i}=\left[n\left\{\int_{0}^{T_{i 1}}\left(h_{i r}+\gamma t\right) I_{i r 1}(t) e^{-R t} d t\right\}+\sum_{m=1}^{n}\left\{\int_{0}^{\left((m-1)+m T_{i 2}\right)}\left(h_{i r}+\gamma t\right) I_{i r 2}(t) e^{-R t} d t\right\}+\int_{0}^{T_{i 3}}\left(h_{i r}+\gamma t\right) I_{i r 3}(t) e^{-R t} d t\right]$ The total number of deteriorated unit is, 


$$
D U_{i}=\left[n \int_{0}^{T_{i 1}} \alpha p_{i} e^{-R t} d t+\int_{0}^{T_{i 3}} p_{i r} e^{-R t} d t\right]-\left[n\left\{\int_{0}^{T_{i 1}} D_{i}(s) e^{-R t} d t+\int_{0}^{T_{i 2}} D_{i}(s) e^{-R t} d t\right\}+\int_{0}^{T_{i 3}} D_{i}(s) e^{-R t} d t+\int_{0}^{T_{i 4}} D_{i}(s) e^{-R t} d t\right]
$$

Deteriorating $\operatorname{Cost}(\mathrm{DC})_{i}=\left(C_{i d}+\frac{C_{d L}}{k^{l}}\right) \cdot D U_{i}$

$$
\text { Production Cost }(\mathrm{PC})_{i}=\eta\left(\mathrm{p}_{i}\right) \int_{0}^{T_{i 1}} \alpha p_{i} e^{-R t} d t+\eta\left(\mathrm{p}_{r i}\right) \int_{0}^{T_{i 3}} \alpha p_{r i} e^{-R t} d t
$$

The total inventory cost is equal to the sum of production setup cost, rework setup cost, serviceable inventory holding cost, recoverable inventory cost, deterioration cost and production cost:

$$
T P\left(T_{i 1}\right)_{i}=(S R)_{i}-\left(S C_{P}\right)_{i}-\left(S C_{R}\right)_{i}-\left(H C_{S}\right)_{i}-\left(H C_{R}\right)_{i}-(D C)_{i}-(P C)_{i}
$$

Total average inventory cost:

$$
\operatorname{TAP}\left(T_{i 1}\right)_{i}=\frac{(S R)_{i}-\left(S C_{P}\right)_{i}-\left(S C_{R}\right)_{i}-\left(H C_{S}\right)_{i}-\left(H C_{R}\right)_{i}-(D C)_{i}-(P C)_{i}}{n\left(T_{i 1}+T_{i 2}\right)+T_{i 3}+T_{i 4}}
$$

To find the optimum solution we have to find the optimum value of $T_{i 1}, T_{i 2}, T_{i 3}$, and $T_{i 4}$ that maximize the total average profit but we have some relations between the variables as follows.

- $\quad I_{i 1}\left(t_{i 1}\right)=I_{i 2}\left(t_{i 2}\right)$ When $t_{i 1}=T_{i 1}$ and $t_{i 2}=0$ :

$$
\frac{1}{\theta_{s}}\left(\alpha_{i} p_{i}-a_{i} s^{-b}\right)\left(1-e^{-\theta_{s} T_{i 1}}\right)=\frac{a_{i} s^{-b}}{\theta_{s}}\left(e^{\theta_{s} T_{i 2}}-1\right)
$$

- $\quad I_{i 3}\left(t_{i 3}\right)=I_{i 4}\left(t_{i 4}\right)$ When $t_{i 3}=T_{i 3}$ and $t_{i 4}=0$ :

$$
\frac{1}{\theta_{s}}\left(p_{r i}-a_{i} s^{-b}\right)\left(1-e^{-\theta_{s} T_{i 3}}\right)=\frac{a_{i} s^{-b}}{\theta_{s}}\left(e^{\theta_{s} T_{i 4}}-1\right)
$$

- $\quad I_{i r 3}\left(t_{i r 3}\right)=I_{M R i}$ When $t_{i r 3}=0$

$$
\frac{p_{r i}}{\theta_{R}}\left(e^{\theta_{R} T_{i 3}}-1\right)=I_{M R i}
$$

\subsection{Solution Procedure}

Using the Eq. (28), Eq. (29) and Eq. (30), we can find the value of $T_{i 2}, T_{i 3}$, and $T_{i 4}$ in terms of $T_{i 1}$ say, $T_{i 2}=f\left(T_{i 1}\right), T_{i 3}=f\left(T_{i 1}\right)$ and $T_{i 4}=f\left(T_{i 1}\right)$

Therefore the total average profit function will be the function of $T_{i 1}$. To maximize the function, taking the first order derivatives of $T A P\left(T_{i 1}\right)_{i}$ with respect to $T_{i 1}$ and equating to zero gives

$$
\frac{d T A P\left(T_{i 1}\right)_{i}}{d}=0
$$

Since the total average profit function Eq.(27) is a nonlinear equation and the second derivative of Eq.(27) with respect to $T_{i 1}$ is extremely complicated, closed form solution cannot be derived. This means that the optimality solution cannot be guaranteed. However, by means of empirical experiments, one can indicate that Eq.(27) is concave for a small value of $T_{i 1}$. The optimal $T_{i 1}$ value can be obtained using a simple search method such as Newton's or Bisection method. Mathematica software is used to validate the empirical experiment results. 


\section{Numerical And Sensitivity Analysis}

\subsection{Numerical Analysis}

The above theoretical results are illustrated through the numerical verification, to illustrate the suggested model we have considered the following input parameters in appropriate units. We have studied this inventory model for two items. The following numerical study has been used to find out the optimal solution of the multi items production and rework model.

The raw data of an illustrative example

$$
\theta_{s}=0.02, \theta_{R}=0.024, \theta=0.04, \xi_{s}=50, \xi_{R}=40, R=0.001, M=2, G=3, H=4, b=0.2
$$

Table 1

The input data

\begin{tabular}{ccccccccccc}
\hline Items $i$ & $a_{i}$ & $\alpha_{i}$ & $p_{i}$ & $p_{r i}$ & $C_{i d}$ & $C_{i p}$ & $C_{i R}$ & $h_{i s}$ & $h_{i R}$ & $S_{i}$ \\
\hline 1 & 80 & 0.8 & 40 & 25 & 8 & 20 & 8 & 3 & 2 & 350 \\
2 & 100 & 0.8 & 50 & 30 & 10 & 30 & 10 & 5 & 3 & 500 \\
\hline
\end{tabular}

Table 2

Optimal solutions for examples

\begin{tabular}{ccccccc}
\hline Items $i$ & $\mathrm{n}$ & $T_{i 1}^{*}$ & $T_{i 2}^{*}$ & $T_{i 3}^{*}$ & $T_{i 4}^{*}$ & $T A P^{*}$ \\
\hline 1 & 3 & 0.110443 & 0.032085 & 0.105438 & 0.000892 & 4734.03 \\
2 & 4 & 0.076860 & 0.029668 & 0.101920 & 0.003105 & 8635.10 \\
\hline
\end{tabular}

The total profit per unit time for varying $T_{i 1}$ and $\mathrm{n}$ is shown in Fig. $4 \& 5$. Fig. 4 and 5 shows that the total profit per unit time is concave for small values of $\mathrm{n}$ and $T_{i 1}$.

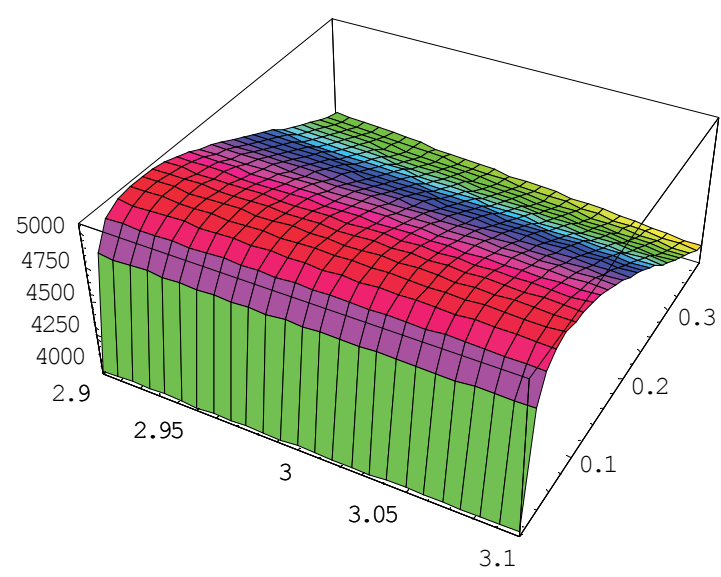

Fig. 4. Concavity of $T A P^{*}$ for first item

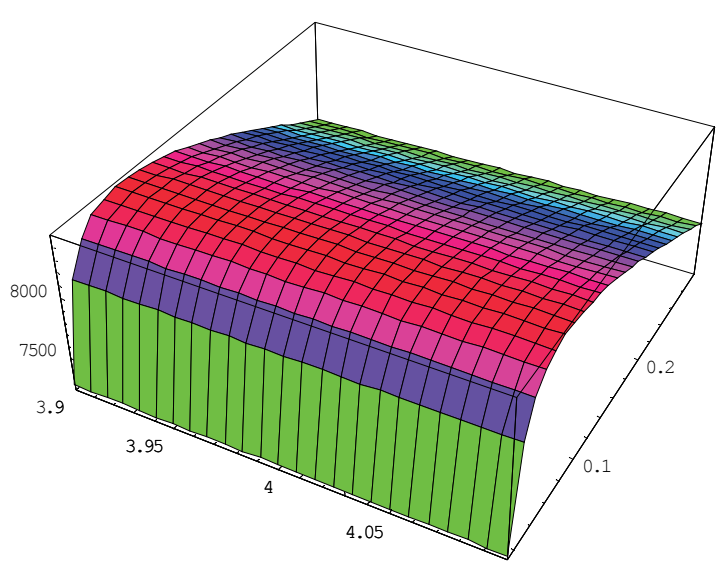

Fig. 5. Concavity of $T A P^{*}$ for second item

\subsection{Sensitivity Analysis}

In every decision-making situation, the variation in the values of parameters may happen due to uncertainties. Using the same data as that in numerical analysis for the first item, we next study the sensitivity of the optimal total average profit and replenishment cycle times to change the values of the different parameters associated with the model The sensitivity analysis is performed by taking one parameter at a time and keeping the remaining parameters unchanged. The computational results are reported in Figs. 6- 8. The results obtained for illustrative examples provide certain insights into the problem as follows: 
Table 3

Effect of changes in the parameters of the inventory

\begin{tabular}{cccccc}
\hline & \multicolumn{2}{c}{ For first item, i.e. $i=1$ and $n=3$} & $T_{i 4}^{*}$ & TAP \\
\hline $\boldsymbol{a}_{\boldsymbol{i}}$ & $T_{i 1}^{*}$ & $T_{i 2}^{*}$ & $T_{i 3}^{*}$ & -- & 6082.89 \\
\hline 100 & 0.2666221 & 0.0086886 & 0.253399 & -- & 5392.19 \\
90 & 0.148907 & 0.0219187 & 0.142035 & 0.000892 & 4734.03 \\
80 & 0.110443 & 0.032085 & 0.105438 & 0.0127326 & 4089.68 \\
\hline 70 & 0.0874717 & 0.0415345 & 0.0835414 & 0.0233001 & 3454.68 \\
\hline 60 & 0.0708284 & 0.0510399 & 0.0676555 & $T_{i 4}^{*}$ & $T A P^{*}$ \\
\hline $\boldsymbol{S}_{\boldsymbol{i}}$ & $T_{i 1}^{*}$ & $T_{i 2}^{*}$ & $T_{i 3}^{*}$ & 0.00203351 & 5166.9 \\
\hline 370 & 0.108001 & 0.0329339 & 0.103115 & 0.0014755 & 4951.32 \\
360 & 0.109189 & 0.0325177 & 0.104246 & 0.000892 & 4734.03 \\
350 & 0.110443 & 0.032085 & 0.105438 & 0.000281579 & 4514.95 \\
340 & 0.111771 & 0.0316384 & 0.106706 & -- & 4294.01 \\
\hline 330 & 0.113179 & 0.0311729 & 0.108047 & $T_{i 4}^{*}$ & $T A P^{*}$ \\
\hline $\boldsymbol{p}_{\boldsymbol{i}}$ & $T_{i 1}^{*}$ & $T_{i 2}^{*}$ & 0.0948666 & 0.000802895 & 4548.92 \\
41 & 0.0945878 & 0.0335834 & 0.0997722 & 0.000844375 & 4641.25 \\
40 & 0.101929 & 0.0329012 & 0.105438 & 0.000892209 & 4734.03 \\
\hline 39 & 0.110443 & 0.032085 & 0.112086 & 0.000948422 & 4827.33 \\
\hline
\end{tabular}

In order to examine the implication of these changes, the sensitivity analysis will be of great help in decision-making.

\subsubsection{Effect of demand rate}

Now, we investigate the effects of varying rate of deteriorating in order to get more insight. Fig. 6 shows the demand rate at $60,70,80,90$, and 100 with other variables remain unchanged. It is shown that as the demand rate increases, the total profit of the inventory system increases.

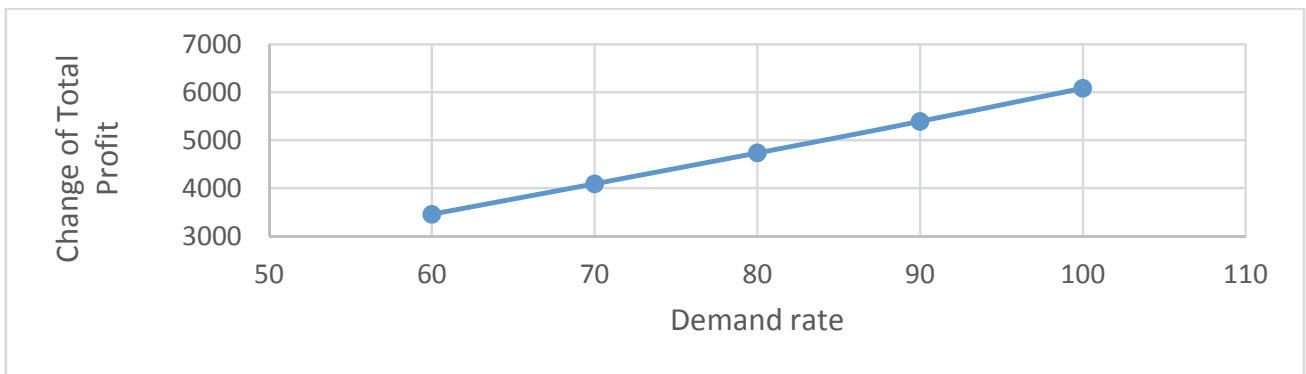

Fig. 6. Effect of demand rate on total profit of the inventory system

\subsubsection{Effect of selling price}

To get the behaviour of proposed model regarding selling price, we investigate its effect on total profit of the inventory system. Fig. 7 reflects the effect of selling price on total profit of the inventory system. It observes that as the selling price increases total profit of the inventory system increases.

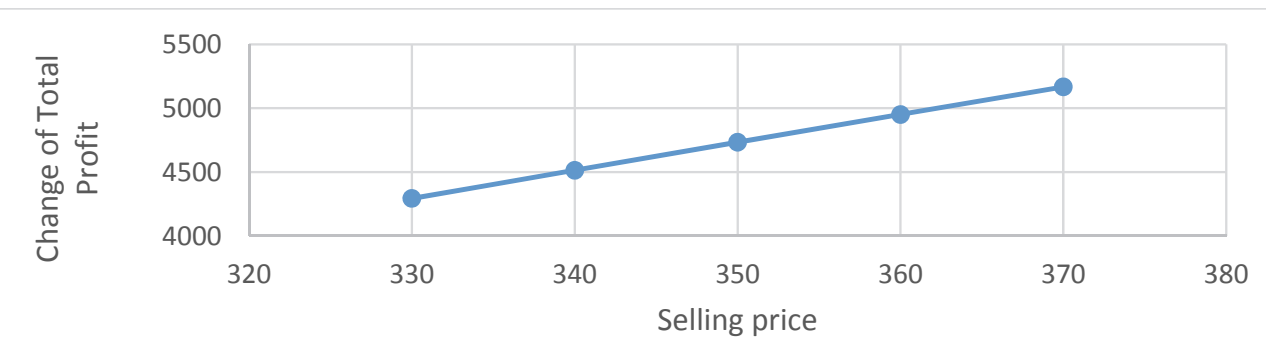

Fig. 7. Effect of selling price on total profit of the inventory system 


\subsubsection{Effect of production rate}

Sensitivity of total profit with respect to production rate has been performed here to get the effect on optimal policy of inventory management. Fig. 8 reflects the effect of production rate on production total profit of the inventory system. It is observed that as the production rate increases total profit of the inventory system decreases. So it is advisable to the decision-maker not to increase the production rate without the prior information about the customer's demand.

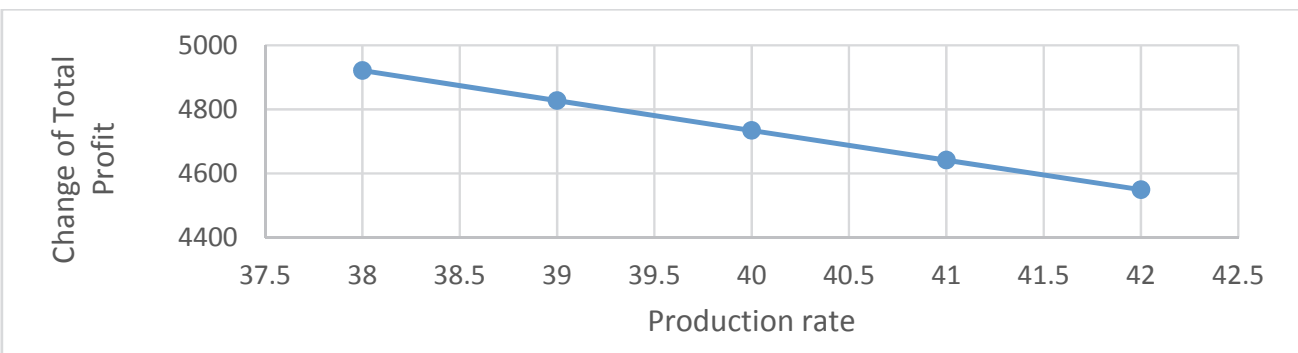

Fig. 8. Effect of production rate on total profit of the inventory system

\section{Conclusion}

This work is an attempt for analyzing a multi-item inventory model with multiple productions, rework and preservation technology investment decision-making problem for a deteriorating inventory system with generalized demand, learning effect on costs, and deterioration rates over an infinite planning horizon. We assume there are $\mathrm{n}$ production setups and one rework setup in each cycle. The proposed model of this paper considers demand as a power function of price and it assumes that production unit cost is a function of the finite production rate. Furthermore, the interest and depreciation costs are also considered as part of modelling formulation. The effect of time value of money on optimal solution is also considered. Hence, all the efforts have been carefully directed towards the possible futuristic enhancements of the model. The optimal replenishment policy for the model is derived for the above mentioned inventory system. Furthermore the sensitivity analysis is presented to study the behaviour of model parameters.

This research can be extended in some directions. For further study, the effect of machine breakdown on this model may be recommended. Besides, it would be interesting to model the problem when various parameters are not deterministic and described in fuzzy or interval form.

\section{References}

Belkaoui, A.R. (1986). The Learning Curve: A Management Accounting Tool. Quorum Books.

Chiu, Y. P. (2003). Determining the optimal lot size for the finite production model with random defective rate, the rework process, and backlogging.Engineering Optimization, 35(4), 427-437.

Crossman, E.R.F.W. (1959). A theory of acquisition of speed skill. Ergonomics, 2(2), 153-166.

Dar-El, E. (2000). Human Learning: From Learning Curves to Learning Organizations. Kluwer Academic Publishers, Dordrecht.

Dave, U., \& Patel, L. K. (1981). (T, $\left.S_{i}\right)$ policy inventory model for deteriorating items with time proportional demand. Journal of the Operational Research Society, 32, 137-142.

Dye, C. Y. (2013). The effect of preservation technology investment on a non-instantaneous deteriorating inventory model. Omega, 41(5), 872-880.

Porteus, E. L. (1986). Optimal lot sizing, process quality improvement and setup cost reduction. Operations Research, 34(1), 137-144.

Feng, Y., \& Viswanathan, S. (2011). A new lot-sizing heuristic for manufacturing systems with product recovery. International Journal of Production Economics, 133(1), 432-438. 
Glock, C. H., \& Jaber, M. Y. (2013). A multi-stage production-inventory model with learning and forgetting effects, rework and scrap. Computers \& Industrial Engineering, 64(2), 708-720.

Lee, H. L., \& Rosenblatt, M. J. (1987). Simultaneous determination of production cycle and inspection schedules in a production system.Management Science, 33(9), 1125-1136.

Hariga, M. (1996). Optimal EOQ models for deteriorating items with time-varying demand. Journal of the Operational Research Society, 47(10),1228-1246.

Hsu, P. H., Wee, H. M., \& Teng, H. M. (2010). Preservation technology investment for deteriorating inventory. International Journal of Production Economics, 124(2), 388-394.

Inderfurth*, K., Lindner, G., \& Rachaniotis, N. P. (2005). Lot sizing in a production system with rework and product deterioration. International Journal of Production Research, 43(7), 1355-1374.

Jaber, M. Y., \& Khan, M. (2010). Managing yield by lot splitting in a serial production line with learning, rework and scrap. International Journal of Production Economics, 124(1), 32-39.

Jaber, M.Y., \& Bonney, M. (2003). Lot sizing with learning and forgetting in set-ups and in product quality. International Journal of Production Economics, 83(1), 95-111.

Lai, E. L.-C. (1995). Learning-by-doing, technology choice, and export promotion. Review of International Economics, 3(2), 186-198.

Laprè, M.A., Mukherjee, A.S., \& Van Wassenhove, L.N. (2000). Behind the learning curve: linking learning activities to waste reduction. Management Science, 46(5), 597-611.

Salameh, M. K., \& Jaber, M. Y. (2000). Economic production quantity model for items with imperfect quality. International journal of production economics, 64(1), 59-64.

Sethi, A. K., \& Sethi, S. P. (1990). Flexibility in manufacturing: a survey.International Journal of Flexible Manufacturing Systems, 2(4), 289-328.

Shastri, A., Singh, S. R., Yadav, D., \& Gupta, S. (2014). Supply chain management for two-level trade credit financing with selling price dependent demand under the effect of preservation technology. International Journal of Procurement Management, 7(6), 695-718.

Singh, S. R., \& Sharma, S. (2013). A global optimizing policy for decaying items with ramp-type demand rate under two-level trade credit financing taking account of preservation technology. Advances in Decision Sciences. http://dx.doi.org/10.1155/2013/126385 Article ID 126385, 12pp.

Singh, S.R., Vaish, B., \& Singh, N. (2012). An economic production lot-size (EPLS) model with rework and flexibility under allowable shortages. International Journal of Procurement Management, 5(1), 104-122.

Teng, J. T., Chern, M. S., Yang, H. L., \& Wang, Y. J. (1999). Deterministic lot-size inventory models with shortages and deterioration for fluctuating demand. Operations Research Letters, 24(1), 65-72.

Tsao, Y. C. (2016). Joint location, inventory, and preservation decisions for non-instantaneous deterioration items under delay in payments. International Journal of Systems Science, 47(3), 572585 .

Wright, T. P. (1936). Factors affecting the cost of airplanes. Journal of the Aeronautical Sciences, 3(4), 122-128.

Yadav, D., Singh, S. R., \& Kumari, R. (2012). Inventory model of deteriorating items with twowarehouse and stock dependent demand using genetic algorithm in fuzzy environment. Yugoslav Journal of Operations Research, 22(1). 51-78.

Yelle, L. E. (1979). The learning curve: Historical review and comprehensive survey. Decision Sciences, 10(2), 302-328.

Hayek, P. A., \& Salameh, M. K. (2001). Production lot sizing with the reworking of imperfect quality items produced. Production Planning \& Control, 12(6), 584-590. 